\title{
EKSPLORASI FUNGI MIKORIZA ARBUSKULA (FMA) PADA RIZOSFIR HIJAUAN PAKAN
}

\author{
Rifa E. Ansiga, A. Rumambi *, D. Kaligis, I. Mansur, W. Kaunang \\ Fakultas Peternakan Universitas Sam Ratulangi Manado, 95115
}

\begin{abstract}
ABSRTAK
Penelitian ini bertujuan untuk mengetahui keanekaragaman FMA pada beberapa rizosfir hijauan pakan unggul baik pada rumput maupun leguminosa. Pengambilan contoh tanah dilakukan di tiga lokasi berbeda, yaitu: Mapanget (jenis hijauan pakan: Leucaena leucocepala, Sorgum varietas numbu, Penicettum purpureum cv. Mott), Tateli (jenis hijauan pakan: Calliandra calothyrsus, Gliricidia Sepium) dan Kampus UNSRAT (jenis hijauan pakan: King grass). Contoh tanah yang sudah diambil dari rizosfir hijauan pakan di Sieving menggunakan Metode Brundrett (metode tuang saring), dilanjutkan dengan sentrifugasi. Kemudian dilakukan isolasi dan identifikasi spora berdasarkan karakter morfologi spora yang meliputi: bentuk, ukuran, warna, hifa attachment dan ornament spora. Hasil ekstraksi dan identifikasi spora pada keenam rizosfir ditemukan 34 spora FMA yang berbeda dalam bentuk dan warna. Pada rumput ditemukan tiga tipe spora yaitu Glomus, Acaulospora dan Sclerocystis. Pada leguminosae ditemukan satu tipe spora yaitu Glomus. Perbedaan rizosfir antara rumput dan leguminosae menyebabkan perbedaan tipe spora, dimana pada rumput terdapat spora Sclerocystis dan Acaulospora, sebaliknya pada leguminosae tidak terdapat Sclerocystis dan Acaulospora.
\end{abstract}

*Korespondensi (corresponding Author) Email: agnitjerumambi@ymail.com
Berdasarkan jumlah spora FMA yang ditemukan tipe Glomus memiliki jumlah yang paling banyak, sedangkan jumlah spora terendah yaitu tipe Sclerocystis dan Acaulospora

Kata Kunci: Eksplorasi, FMA, Rumput, Legum, Spora

\section{ABSTRACT}

EXPLORATION OF ARBUSCULAR
MYCORRHIZAL (AM) FUNGI IN
FORAGE RHIZOSPHERES. This study aimed to determine the diversity of Arbuscular Mycorrhizal Fungi (AMF) in several kinds of hybrid forages Rhizospheres, either in grasses or legumes. Soil samples were taken from three different locations, consisted of: Mapanget (forages type: Leucaena leucocepala, Sorghum varieties numbu, Penicettum purpureum cv. Mott), Tateli (forages type: calothyrsus Calliandra, Gliricidia sepium) and Campus of UNSRAT, Manado (forage type: King grass). The soil samples which taken from forages rhizospheres were sieved using Brundrett method and then centrifuged. Thereafter, isolation and identification of spore were carried out based on spore morphology character, involves: shape, size, color, hyphae attachment, and ornament. Extraction and identification of spores on six types of rhizosphere were found 34 different types of AMF spores in shape and color. In grass, it was found three types of spores, i.e.: Glomus, Acaulospora, and Sclerocystis, meanwhile in leguminous 
just one type of spore was found, i.e.: Glomus. The difference of rhizosphere in grass and leguminosae resulted in different types of spores, where Sclerocystis and Acaulospora are found in grasses, on the contrary Sclerocystis and Acaulospora are not found in leguminosae. Based on the number of spores of AMF, it seemed that Glomus types found to have the most number, while Sclerocystis and Acaulospora had the lowest number of spores found.

Key words: Exploration, Arbuscular Mycorrhizal Fungi (AMF), Grass, Legume, Spores

\section{PENDAHULUAN}

Hijauan merupakan sumber bahan pakan ternak yang utama dan sangat besar peranannya bagi ternak ruminansia (sapi, kerbau, kambing dan domba) baik untuk hidup pokok, produksi maupun reproduksi. Di Indonesia umumnya hijauan tumbuh atau dibudidayakan biasanya hanya memanfaatkan lahan - lahan marginal atau lahan yang mempunyai tingkat kesuburan rendah, sehingga produksi dan kualitas hijauan yang dihasilkan rendah, tercermin dari produksi ternak yang dihasilkan juga rendah. Untuk meningkatkan kesuburan tanah perlu alternatif pemanfaatan tehnologi yang ramah lingkungan dengan pemanfaatan Fungi Mikoriza Arbuskula (FMA) sebagai agensi hayati pada jenis tanaman dapat membantu dalam meningkatkan efisiensi penyerapan unsur hara. Mengingat peran fungsional FMA dapat dimanfaatkan untuk berbagai kepentingan antara lain meningkatkan jumlah dan mutu hasil tanaman, mengurangi kebutuhan pupuk dan pestisida, mengurangi erosi, mereduksi emisi $\mathrm{CO}_{2}$ dan menyuburkan tanah (Nusantara et al., 2012).

FMA dapat membentuk simbiosis mutualisme dengan perakaran tumbuhan, sehingga dapat membantu tanaman menjadi lebih baik, dimana keduanya mendapatkan keuntungan antara lain FMA mendapatkan sumber karbon dari hasil fotosintesis sementara tanaman mendapatkan pasokan unsur hara dari FMA. Fungi Mikoriza Arbuskula dalam berbagai kajian dapat meningkatkan produktivitas tanaman sekitar 25\%-50\% yang meliputi, kesehatan tanaman, kualitas hasil, toleransi terhadap cekaman air, efisiensi pemupukan dan dapat menekan perkembangan mikroba patogen dalam tanah.

FMA banyak menyebar terutama pada famili gramineae dan leguminosae serta memiliki tempat hidup yang khusus atau memiliki inang yang spesifik. Ada beberapa jenis FMA menunjukkan spesifikasi untuk memilih dan berasosiasi dengan jenis inang tertentu (Setiadi, 1990). Perbedaan lokasi dan rizosfir menyebabkan perbedaan keanekaragaman spesies dan populasi FMA. 
Penelitian tentang eksplorasi FMA pada risosfir rumput dan legum di Sulawesi Utara belum pernah dilakukan, oleh sebab itu melalui penelitian ini diharapkan akan menjadi awal untuk mengetahui dan memperoleh gambaran keanekaragaman FMA yang ada di Sulawesi Utara.

\section{MATERI DAN METODE PENELITIAN}

\section{Tempat dan Waktu Penelitian}

Penelitian dilaksanakan pada bulan Juli sampai Agustus 2016. Penelitian ini terdiri dari dua tahap. Tahap pertama pengambilan contoh tanah pada rizosfir tanaman rumput dan leguminosa unggul. Pada tahapan ini dilaksanakan pada 3 (tiga) tempat yaitu daerah Mapanget (Leucaena Leucepala, sorgum numbu, panicettum purpureum cv. Moot, kemudian daerah Tateli (Caliandra Calothrysus, Glicidia Sepium) serta daerah Kampus Bahu Manado (King Gress). Tahap kedua yaitu penyaringan spora (sieving), penangkaran spora (trapping), isolasi dan identifikasi jenis spora (morfologi, ukuran, warnah, struktur sub seluler). Pada Tahapan jkedua ini dilaksanakan di Laboratorium SEAMEO BIOTROP Bogor.

\section{Materi Penelitian}

Materi yang digunakan adalah tanah Risosfir Hijauan Pakan unggul (rumput dan leguminosa). Alat - alat yang digunakan adalah cangkul/parang, kantong plastik, spidol, kertas lebel dan kamera. Alat yang digunakan di laboratorium untuk isolasi dan identifikasi FMA adalah gelas ukur dan gelas piala, centrifuse dan tabung centrifuse, Mikroskop compound dan binoculer, timbangan analitik, saringan spora $(425 \mu \mathrm{m}, 212 \mu \mathrm{m}, 106$ dan $45 \mu \mathrm{m})$, cawan Petri kaca, pinset spora mikro, pengaduk, kaca objek, kaca penutup, kertas saringan $(0,5 \mu \mathrm{m})$, pipet, multiwer, aluminium foil, labu Erlenmeyer, hot plate magnetic stirer dan alat tulis menulis. Isolasi dan identifikasi spora FMA dibutuhkan bahan berupa air, Glukosa 60\%, Larutan Melzer's dan larutan polyvinil lactoglycerol (PVLG).

\section{Metode Penelitian}

\section{a. Eksplorasi Fungi Mikoriza Arbuskula (FMA) pada risosfir hijauan pakan unggul.}

Pengambilan sampel tanah dari rizosfir tanaman yang diuji, mula - mula dengan membersikan area tanaman dari rumput - rumput liar yang ada, selanjutnya mengambil sampel tanah sebanyak 500 gram dengan kedalaman $0-20 \mathrm{~cm}$, kemudian dicampurkan secara komposit. Tanah selanjutnya dimasukkan ke dalam 
kantong plastik kemudian diberi label yang tertulis jenis tanaman, lokasi pengambilan dan tanggal pengambilan.

\section{b. Isolasi Spora Mikoiza}

Teknik yang digunakan dalam mengisolasi dengan metode tuang - saring (Pacioni, 1992) dilanjutkan dengan metode sentrifugasi (Brundrett et al.,1996). Langkah kerja dari teknik tuang saring adalah menimbang sampel tanah sebanyak 20 gram kemudian mencampurkan sampel tanah sebanyak 20 gram dengan $200-300$ $\mathrm{ml}$ air dan diaduk secara merata, selanjutnya disaring dalam satu set saringan dengan ukuran $425 \mu \mathrm{m}, 212 \mu \mathrm{m}$, 106 dan $63 \mu \mathrm{m}$ secara berurutan dari atas ke bawah. Pada saringan bagian atas disemprot dengan air kran untuk memudahkan bahan saringan lolos. Bahan yang lolos pada saring bawah dan kedua dari paling bawah selanjutnya dipindahkan ke dalam tabung sentrifuse.

Bahan kemudian disentrufugasi dengan teknik sentifugasi (Brundrett et al., 1996). Hasil saringan ditambah dengan Glukosa $60 \%$. Tabung sentrifuse ditutup rapat dan disentrifugasi dengan kecepatan $3000 \mathrm{rpm}$ selama 5 menit. Selanjutnya larutan supernatan dituang ke dalam kertas saringan $0,5 \mathrm{~mm}$, dibilas dengan aquades mengalir untuk menghilangkan glukosa. Endapan yang tersisa dimasukkan ke dalam cawan Petri dan kemudian dilakukan pengamatan spora menggunakan mikroskop compound untuk menghitung jumlah populasi spora per sampel.

\section{c. Identifikasi Mikoriza}

Pembuatan preparat spora dimaksudkan untuk membantu dalam proses identifikasi. Dari preparat tersebut diharapkan informasi morfologi spora dapat menentukan genus FMA. Identifikasi dilakukan dengan menggunakan mikroskop compound dengan bantuan mikroskop binoculer dan pinset spora. Spora yang diperoleh dikumpulkan berdasarkan karakter morfologi spora mikoriza meliputi: bentuk spora, ukuran spora, warna spora, hifa attachment dan ornament spora.

\section{HASIL DAN PEMBAHASAN}

Hasil ekstraksi dan identifikasi spora yang dilakukan pada enam jenis risozfir ditemukan 34 tipe spora FMA yang berbeda. Tipe spora yang diperoleh pada rumput ditemukan tiga genus spora yaitu Glomus, Acaulospora dan Sclerocystis. Pada legume ditemukan satu genus spora yaitu Glomus. Perbedaan rizosfir antara rumput dan legum menyebabkan perbedaan tipe spora, dimana pada rumput terdapat spora Sclerocystis dan Acaulospora, sebaliknya 
Tabel 1. Karakteristik dan tipe spora yang diisolasi dari rizosfer tanaman Sorgum varietas numbu asal Mapanget

\begin{tabular}{|c|c|c|c|}
\hline No & Jenis Spora & Deskripsi Morfologi & $\begin{array}{c}\text { Reaksi dengan } \\
\text { Melzer's } \\
\end{array}$ \\
\hline 1. & Glon & $\begin{array}{l}\text { Spora oval licin, warna kuning memiliki } \\
\text { hifa. Lolos saringan } 106 \mu \mathrm{m} \text {. }\end{array}$ & $\begin{array}{l}\text { Tidak ada reaksi } \\
\text { pada saat ditetesi } \\
\text { larutan Melzer's }\end{array}$ \\
\hline 2. & Glomus sp.2 & $\begin{array}{l}\text { Spora oval, warna coklat memiliki hifa } \\
\text { lolos saringan } 106 \mu \mathrm{m} .\end{array}$ & $\begin{array}{l}\text { Tidak ada reaksi } \\
\text { pada saat ditetesi } \\
\text { larutan Melzer's }\end{array}$ \\
\hline 3. & $\operatorname{sp.3}$ & $\begin{array}{l}\text { Spora bulat, warna coklat muda memiliki } \\
\text { dinding yang tebal memiliki hifa lolos } \\
\text { saringan } 106 \mu \mathrm{m} \text {. }\end{array}$ & $\begin{array}{l}\text { Tidak ada reaksi } \\
\text { pada saat ditetesi } \\
\text { larutan Melzer's }\end{array}$ \\
\hline 4. & $\operatorname{sp.4}$ & $\begin{array}{l}\text { Spora bulat licin, warna kuning ada sisi } \\
\text { hifa, berdinding tebal lolos saringan } 106 \\
\mu \mathrm{m} .\end{array}$ & $\begin{array}{l}\text { Tidak ada reaksi } \\
\text { pada saat ditetesi } \\
\text { larutan Melzer's }\end{array}$ \\
\hline 5. & sp.5 & $\begin{array}{l}\text { Spora tidak beraturan, warna coklat lolos } \\
\text { saringan } 106 \mu \mathrm{m} .\end{array}$ & $\begin{array}{l}\text { Tidak ada reaksi } \\
\text { pada saat ditetesi } \\
\text { larutan Melzer's }\end{array}$ \\
\hline 6. & Glomus sp.6 & $\begin{array}{l}\text { Spora bulat, warna hialin lolos saringan } \\
106 \mu \mathrm{m} .\end{array}$ & $\begin{array}{l}\text { Tidak ada reaksi } \\
\text { pada saat ditetesi } \\
\text { larutan Melzer's }\end{array}$ \\
\hline 7. & Glomus sp.7 & $\begin{array}{l}\text { Spora bulat, warna coklat muda memiliki } \\
\text { dinding yang tebal lolos saringan } 212 \\
\mu \mathrm{m} .\end{array}$ & $\begin{array}{l}\text { Tidak ada reaksi } \\
\text { pada saat ditetesi } \\
\text { larutan Melzer's }\end{array}$ \\
\hline 8. & Glomus sp.8 & $\begin{array}{l}\text { Spora bulat, warna coklat lolos saringan } \\
212 \mu \mathrm{m} \text {. }\end{array}$ & $\begin{array}{l}\text { Tidak ada reaksi } \\
\text { pada saat ditetesi } \\
\text { larutan Melzer's }\end{array}$ \\
\hline 9. & Sclerocystis sp.1 & $\begin{array}{l}\text { Spora bulat bergerigi, warna kuning } \\
\text { lolos saringan } 106 \mu \mathrm{m} \text {. }\end{array}$ & $\begin{array}{l}\text { Tidak ada reaksi } \\
\text { pada saat ditetesi } \\
\text { larutan Melzer's }\end{array}$ \\
\hline
\end{tabular}

sebaliknya pada legume tidak terdapat Sclerocystis dan Acaulospora.

Karakteristik masing - masing tipe spora yang ditemukan memiliki ciri khas, seperti tipe Glomus terdapat dudukan hifa (subtending hiphae), Acaulospora memiliki dinding yang tebal dan spora memiliki ornament, sedangkan Sclerocystis memiliki dinding seperti kulit jeruk (Suamba et al., 2014). Karakteristik tipe spora yang diisolasi dari rizosfer hijauan pakan dapat dilihat pada Tabel 1, $2,3,4,5$ dan 6 . 
Tabel 2. Karakteristik dan tipe spora yang diisolasi dari rizosfir rumput Gajah Mini (Pennicetum purpurem cv. Mott) asal Mapanget

\begin{tabular}{|c|c|c|}
\hline Jenis Spora & Deskripsi Morfologi & Reaksi dengan Melzer'z \\
\hline 1. Glomus sp.1 & $\begin{array}{l}\text { Spora elips licin, hialin } \\
\text { memiliki hifa. Lolos pada } \\
\text { saringan } 106 \mu \mathrm{m} .\end{array}$ & $\begin{array}{l}\text { Tidak ada reaksi pada saat } \\
\text { ditetesi larutan Melzer's }\end{array}$ \\
\hline 2. Glomus sp. 2 & $\begin{array}{l}\text { Spora elips hitam, warna } \\
\text { kuning dan dindingnya } \\
\text { berwarna hitam memiliki hifa. } \\
\text { Lolos pada saringan } 106 \mu \mathrm{m} .\end{array}$ & $\begin{array}{l}\text { Tidak ada reaksi pada saat } \\
\text { ditetesi larutan Melzer's }\end{array}$ \\
\hline 3. Glor & $\begin{array}{l}\text { Spora elips hitam, warna } \\
\text { kuning lolos pada saringan } \\
106 \mu \mathrm{m} \text {. }\end{array}$ & $\begin{array}{l}\text { Tidak ada reaksi pada saat } \\
\text { ditetesi larutan Melzer's }\end{array}$ \\
\hline 4. Glomus sp.4 & $\begin{array}{l}\text { Spora elips, warna hialin } \\
\text { memiliki dinding yang tebal } \\
\text { bergerigi. Lolos pada saringan } \\
212 \mu \mathrm{m} \text {. }\end{array}$ & $\begin{array}{l}\text { Tidak ada reaksi pada saat } \\
\text { ditetesi larutan Melzer's }\end{array}$ \\
\hline 5. Acaulospora sp.1 & $\begin{array}{l}\text { Spora bulat licin, warna } \\
\text { coklat muda. Lolos pada } \\
\text { saringan } 212 \mu \mathrm{m} .\end{array}$ & $\begin{array}{l}\text { Bereaksi dengan larutan } \\
\text { Melzer pada bagian dalam } \\
\text { menjadi coklat, bagian } \\
\text { luarnya kuning }\end{array}$ \\
\hline
\end{tabular}

Berdasarkan jumlah genus spora FMA yang ditemukan, Glomus memiliki jumlah yang paling banyak diikuti Sclerocystis, sedangkan jumlah spora terendah yang ditemukan yaitu Acaulospora. Glomus yang paling dominan dan ditemukan pada semua jenis rumput dan legume yang diamati. Secara keseluruhan Glomus memiliki jumlah yang paling tinggi dibanding 2 genus lainnya. melimpahnya Glomus disebabkan secara umum mikoriza tersebut cocok dengan habitatnya.

Kemampuan fungi untuk beradaptasi dengan kondisi lokal cukup tinggi. Hal tersebut menunjukkan bahwa faktor lokasi sangat berpengaruh terhadap kelimpahan mikoriza (Hidayat dan Salim, 2003). Perbedaan lokasi dan rizosfir menyebabkan perbedaan keanekaragaman spesies dan populasi FMA (Sundari et al., 2011). Hasil penelitian Nurhatika et al. (2014) menunjukkan bahwa Glomus merupakan spora FMA yang dominan dibanding Acaulospora dan Gigaspora di daerah Pamekasan Madura.

Keanekaragaman spora FMA disebabkan antara lain perbedaan tingkat kesuburan tanah, kandungan bahan organik, intensitas cahaya dan ketinggian di atas permukaan laut (Setiadi, 1989). 
Tabel 3. Karakteristik Dan Tipe Spora Yang Diisolasi Dari Rizosfir Tanaman Rumput Raja (King Grass) Asal Kampus Bahu.

\begin{tabular}{|c|c|c|}
\hline No Jenis Spora & Deskripsi morfologi & Reaksi dengan Melzer's \\
\hline 1. Glomus sp.1 & $\begin{array}{l}\text { Spora bulat, warna hialin ada } \\
\text { sisa hifa lolos pada saringan } 106 \\
\mu \mathrm{m} .\end{array}$ & $\begin{array}{l}\text { Tidak ada reaksi pada } \\
\text { saat ditetesi larutan } \\
\text { Melzer's }\end{array}$ \\
\hline 2. Glomus sp.2 & $\begin{array}{l}\text { Spora bulat permukaan tidak } \\
\text { rata, warna hialin lolos pada } \\
\text { saringan } 106 \mu \mathrm{m} .\end{array}$ & $\begin{array}{l}\text { Tidak ada reaksi pada } \\
\text { saat ditetesi larutan } \\
\text { Melzer's }\end{array}$ \\
\hline 3. Glc & $\begin{array}{l}\text { Spora tidak beraturan, warna } \\
\text { hialin lolos pada saringan } 212 \\
\mu \mathrm{m} .\end{array}$ & $\begin{array}{l}\text { Tidak ada reaksi pada } \\
\text { saat ditetesi larutan } \\
\text { Melzer's }\end{array}$ \\
\hline 4. Glomus sp.4 & $\begin{array}{l}\text { Spora bulat licin, warna hialin } \\
\text { memiliki dinding yang tebal. } \\
\text { Lolos pada saringan } 212 \mu \mathrm{m} .\end{array}$ & $\begin{array}{l}\text { Tidak ada reaksi pada } \\
\text { saat ditetesi larutan } \\
\text { Melzer's }\end{array}$ \\
\hline 5. Glomus sp.5 & $\begin{array}{l}\text { Spora bulat, warna kuning. Lolos } \\
\text { saringan } 212 \mu \mathrm{m} \text {. }\end{array}$ & $\begin{array}{l}\text { Tidak ada reaksi pada } \\
\text { saat ditetesi larutan } \\
\text { Melzer's }\end{array}$ \\
\hline 6. Sclerocystis sp.1 & $\begin{array}{l}\text { Spora tidak beraturan, warna } \\
\text { orange lolos saringan } 106 \mu \mathrm{m} \text {. }\end{array}$ & $\begin{array}{l}\text { Tidak ada reaksi pada } \\
\text { saat ditetesi larutan } \\
\text { Melzer's }\end{array}$ \\
\hline
\end{tabular}

Hasil eksplorasi FMA di bawah tegakan kelapa rozosfir Arachis pintoi adalah jenis Acaulospora-sp, Glomus-sp, Gigaspora-sp dan Sclerocystis-sp (Rumambi, 2012). Jumlah dan jenis spora mikoiza yang ditemukan dipengaruhi oleh adanya tanaman yang menjadi inangnya (Nurhatika et al., 2014). Perbedaan lokasi dan risosfir menyebabkan perbedaan keanekaragaman spesies dan populasi FMA (Baon, 2000).

Keanekaragaman spora merupakan kekayaan jenis spora hasil identifikasi sampai pada tingkat genus. Identifikasi
FMA dilakukan dengan bantuan larutan Melzer. Genus Glomus dan Sclerocystis tidak bereaksi terhadap larutan Melzer. Genus Acaulospora pada lapisan luar tidak bereaksi dengan larutan Melzer tetapi lapisan dalam bereaksi dengan Melzer dengan adanya perubahan warna menjadi merah kecoklatan. Genus spora FMA yang ditemukan adalah Glomus, Sclerocystis dan Acaulospora.

Hasil pengamatan memperlihatkan bahwa jumlah spora terbanyak diperoleh pada tanaman-tanaman seperti sorgum varietas numbuh, rumput raja (king grass), 
kaliandra (Calliandra calothyrsus) dan lamtoro (Leucaena leucocepala). Berdasarkan Tabel 1, 2, 3, 4, 5 dan 6 dapat dilihat bahwa jumlah spora pada tanaman rumput menghasilkan keanekaragaman spora lebih banyak dibandingkan dengan keanekaragaman spora pada leguminosa. Hal ini kemungkinan karena tanaman rumput merupakan tanaman yang sesuai untuk perbanyakan spora Glomus dan mempunyai sistem perakaran yang sesuai untuk perkembangan dan sporulasi spora Glomus (Wulandari et al., 2014). Menurut Widiastuti dan Kramadibrata (1992), simbiosis FMA dengan tanaman sangat dipengaruhi oleh jenis tanah, jenis tanaman, jenis FMA dan interaksi antara ketiganya. Jenis tanaman memperlihatkan perbedaan jenis spora FMA dimana hampir sebagian besar tanaman rumput yang diamati ditemukan spora dalam jumlah yang lebih besar dibandingkan pada tanaman legum pohon. Mikoriza yang telah berasosiasi dengan akar tanaman untuk menyerap unsur hara $\mathrm{P}$ dan N (Jia et al., 2014) maupun memperbaiki struktur tanah (Musfal, 2010). Perbedaan tanaman inang dan kesuburan tanah mempengaruhi perbedaan jumlah populasi FMA (Ismahan, 1998).

Tabel 4. Karakteristik dan tipe spora yang diisolasi dari rizosfir tanaman kaliandra (Caliandra calothyrsus) asal Tateli

\begin{tabular}{|c|c|c|}
\hline No Jenis Spora & Deskripsi Morfologi & Reaksi dengan Melzer'z \\
\hline 1. Glomus sp.1 & $\begin{array}{l}\text { Spora bulat licin, berwarna coklat } \\
\text { tua kemerahan, memiliki hifa. } \\
\text { Lolos saringan } 106 \mu \mathrm{m} \text {. }\end{array}$ & $\begin{array}{c}\text { Tidak ada reaksi pada saat } \\
\text { ditetesi larutan Melzer's }\end{array}$ \\
\hline 2. Glo & $\begin{array}{l}\text { Spora tidak beraturan, warna } \\
\text { coklat muda, memiliki hifa. } \\
\text { Lolos saringan } 106 \mu \mathrm{m} .\end{array}$ & $\begin{array}{c}\text { Tidak ada reaksi pada saat } \\
\text { ditetesi larutan Melzer's }\end{array}$ \\
\hline 3. Glor & $\begin{array}{l}\text { Spora bulat, warna hialin } \\
\text { berdinding tipis memiliki hifa. } \\
\text { Lolos saringan } 106 \mu \mathrm{m} \text {. }\end{array}$ & $\begin{array}{l}\text { Tidak ada reaksi pada saat } \\
\text { ditetesi larutan Melzer's }\end{array}$ \\
\hline 4. $G l$ & $\begin{array}{l}\text { Spora bulat, warna coklat tua } \\
\text { lolos saringan } 212 \mu \mathrm{m} \text {. }\end{array}$ & $\begin{array}{l}\text { Tidak ada reaksi pada saat } \\
\text { ditetesi larutan Melzer's }\end{array}$ \\
\hline 5. Glomus sp.5 & $\begin{array}{l}\text { Spora bulat, warna hialin lolos } \\
\text { pada saringan } 212 \mu \mathrm{m} \text {. }\end{array}$ & $\begin{array}{c}\text { Tidak ada reaksi pada saat } \\
\text { ditetesi larutan Melzer's }\end{array}$ \\
\hline 6. Glomus sp.6 & $\begin{array}{l}\text { Spora bulat, warna kuning } \\
\text { berdinding tebal, memiliki hifa } \\
\text { dan bulbous. Lolos pada saringan } \\
212 \mu \mathrm{m} \text {. }\end{array}$ & $\begin{array}{l}\text { Tidak ada reaksi pada saat } \\
\text { ditetesi larutan Melzer's }\end{array}$ \\
\hline
\end{tabular}


Tabel 5. Karakteristik dan tipe spora yang diisolasi dari rizosfir tanaman Gliricidia sepiumasal Tateli

\begin{tabular}{|c|c|c|c|}
\hline No & Jenis Spora & Deskripsi Morfologi & $\begin{array}{l}\text { Reaksi dengan } \\
\text { Melzer'z }\end{array}$ \\
\hline 1. & Glom & $\begin{array}{l}\text { Spora bulat, warna hialin memiliki } \\
\text { dinding yang tebal. Lolos saringan } \\
106 \mu \mathrm{m} .\end{array}$ & $\begin{array}{l}\text { Tidak ada reaksi } \\
\text { pada saat ditetesi } \\
\text { larutan Melzer's }\end{array}$ \\
\hline & Glomus sp. 2 & $\begin{array}{l}\text { Spora bulat, warna orange kecoklatan } \\
\text { lolos pada saringan } 212 \mu \mathrm{m} \text {. }\end{array}$ & $\begin{array}{l}\text { Tidak ada reaksi } \\
\text { pada saat ditetesi } \\
\text { larutan Melzer's }\end{array}$ \\
\hline 3. & Glomus sp.3 & $\begin{array}{l}\text { Spora bulat, warna hialin memiliki } \\
\text { dinding yang tebal. Lolos pada } \\
\text { saringan } 212 \mu \mathrm{m} .\end{array}$ & $\begin{array}{l}\text { Tidak ada reaksi } \\
\text { pada saat ditetesi } \\
\text { larutan Melzer's }\end{array}$ \\
\hline & Glomus sp.4 & $\begin{array}{l}\text { Spora bulat, warna coklat tua memiliki } \\
\text { hifa dan bulbous. Lolos pada saringa } \\
212 \mu \mathrm{m} \text {. }\end{array}$ & $\begin{array}{l}\text { Tidak ada reaksi } \\
\text { pada saat ditetesi } \\
\text { larutan Melzer's }\end{array}$ \\
\hline
\end{tabular}

Tabel 6. Karakteristik dan tipe spora yang diisolasi dari rizosfir tanaman Leucaena leucocephala asal Mapanget

\begin{tabular}{|c|c|c|c|}
\hline No & Jenis Spora & Deskripsi Morfologi & $\begin{array}{l}\text { Reaksi dengan } \\
\text { Melzer'z }\end{array}$ \\
\hline 1. & Glomus sp.1 & $\begin{array}{l}\text { Spora tidak beraturan, warna orange } \\
\text { memiliki hifa. Lolos pada saringan } \\
106 \mu \mathrm{m} .\end{array}$ & $\begin{array}{l}\text { Tidak ada reaksi pada } \\
\text { saat ditetesi larutan } \\
\text { Melzer's }\end{array}$ \\
\hline 2. & Glomus sp. 2 & $\begin{array}{l}\text { Spora bulat, warna orange memiliki } \\
\text { dinding yang tebal dab ada sisa hifa. } \\
\text { Lolos pada saringan } 106 \mu \mathrm{m} \text {. }\end{array}$ & $\begin{array}{l}\text { Tidak ada reaksi pada } \\
\text { saat ditetesi larutan } \\
\text { Melzer's }\end{array}$ \\
\hline 3. & Glomus sp.3 & $\begin{array}{l}\text { Spora bulat, warna hialin lolos pada } \\
\text { saringan } 106 \mu \mathrm{m} .\end{array}$ & $\begin{array}{l}\text { Tidak ada reaksi pada } \\
\text { saat ditetesi larutan } \\
\text { Melzer's }\end{array}$ \\
\hline 4. & Glomus sp.4 & $\begin{array}{l}\text { Spora tidak beraturan, warna hialin } \\
\text { lolos pada saringan } 212 \mu \mathrm{m} \text {. }\end{array}$ & $\begin{array}{l}\text { Tidak ada reaksi pada } \\
\text { saat ditetesi larutan } \\
\text { Melzer's }\end{array}$ \\
\hline 5. & us sp.5 & $\begin{array}{l}\text { Spora bulat licin, warna kuning dan } \\
\text { memiliki ornament lolos pada } \\
\text { saringan } 212 \mu \mathrm{m} .\end{array}$ & $\begin{array}{l}\text { Tidak ada reaksi pada } \\
\text { saat ditetesi larutan } \\
\text { Melzer's }\end{array}$ \\
\hline 6. & Glomus sp.6 & $\begin{array}{l}\text { Spora bulat, warna kuning memiliki } \\
\text { dinding tebal. Lolos pada saringan } \\
212 \mu \mathrm{m} \text {. }\end{array}$ & $\begin{array}{l}\text { Tidak ada reaksi pada } \\
\text { saat ditetesi larutan } \\
\text { Melzer's }\end{array}$ \\
\hline
\end{tabular}

Satu jenis FMA dapat menginfeksi lebih dari satu jenis tanaman inang, dimana penyebaran FMA paling luas adalah Glomus diikuti Sclerocystis. Glomus jumlahnya paling mendominasi yang ditemukan pada setiap tiga lokasi 
jenis rumput dan legum. Menurut Clark (1997), Glomus memiliki masa dorminasi yang paling singkat, mempunyai daya kecambah cukup baik dan waktu kecambah paling cepat diantara genus mikoriza yang lain ( $\pm \quad 6$ minggu), sedangkan penyebaran genus FMA yang paling sempit adalah Acaulospora dan Sclerocystis. Penyebaran Sclerocystis ini hanya ditemukan pada 2 jenis tanaman rumput dari 6 jenis hijauan pakan yang diamati, antara lain yaitu Sorgum varietas numbu dan rumput raja (King grass) dengan jumlah spora yang ditemukan relatif sedikit yaitu 1 spora/20 gram contoh tanah. Hal ini menunjukkan bahwa Glomus mempunyai tingkat adaptasi yang cukup tinggi terhadap lingkungan baik pada kondisi tanah yang masam maupun netral (Suamba et al., 2014). Tanah dengan fraksi lempung juga merupakan tanah yang baik bagi perkembangan Glomus (Koskey, 1987).

FMA merupakan pupuk yang hanya cukup sekali diberikan seumur hidup tanaman asalkan ada tanaman inang, karena FMA merupakan makluk hidup yang dapat terus tumbuh dan berkembang (Setiadi dan Setiawan, 2011). Dalam penelitian ini spora FMA yang ditemukan pada umumnya berbentuk tunggal. Glomus, Acaulospora dan Sclerocystis yang ditemukan memiliki jenis yang beranekaragam. Hal ini terlihat dari penampilan warna, bentuk, ukuran dan dinding spora yang berbeda.

\section{KESIMPULAN}

Berdasarkan hasil eksplorasi dan identifikasi terhadap FMA yang terdapat pada jenis hijauan rumput dan leguminosa menunjukkan bahwa terdapat 3 (tiga) keanekaragaman genus FMA yakni Glomus, Acaulospora dan Sclerocystis.

\section{DAFTAR PUSTAKA}

Allen, E.B., M.F. Allen, D. J. Helm, J. M. Trappe, R. Molina, E. Rincon. 1995. Patten and regulation of mycorrhizal plant and fungal diversity. Plant and Soil. Vol. 170(1): 47-62.

Baon, J.B. 2000. Status Penelitian Cendawan Mikoriza Arbuskula (CMA) Pada Tanaman Perkebunan. Prosiding Seminar Mikoriza I. Bogor.

Brundrett, M., B. Neale, D. Bernei, G. Tim dan M. Nick. 1996. Working With Mycorrhizas in Forestry and Agriculture. Australian Centre for International Agriculture Research (ACIAR), Canbera - Australia Vol. 11(1995): 34-39

Clark, R. B. 1997. Arbuskular Mycorrhizal Adaption, Spora Germination, Root Colonization and Host Plant Growth and Mineral Acquisition at Low pH. Plant and Soil 192:15-22

Hidayat, C. dan M. A. Salim, 2003. Studi keanekaragaman cendawan 
mikoriza arbuskula di bawah tegakan hutan tanaman industry. Fakultas Kehutanan Universitas Winaya Mukti Bandung. Prosiding Seminar Mikoriza Bandung. hal: 41-48.

Ismahan, I. 1998. Studi Keanekaragaman dan Potensi Inokulum Fungi Glomalean pada Beberapa Tipe Pemanfaatan Lahan di Jambi. Thesis. Program Studi Biologi. Pasca Sarjana UI-Depok, Jakarta.

Jia, Y. V., M. Gray, C. J. Straker. 2014. The influence of rhizobium and arbuscular mycorrhizal fungi on nitrogen and phosphorus accumulation by Vicia faba. Animal of Botani 94:251-258.

Koskey, R. E. 1987. Distribution of VA Mycorrhizal fungi along a latitudinal temperature gradient. Mycologia, Vol. 79(1): 55-68.

Musfal, 2010. Potensi cendawan mikoriza arbuskula untuk meningkatkan hasil tanaman jagung. Jurnal Litbang Pertanian. Vol 29(4): 154158.

Nurhatika, S., N. Kadek, M. D. Cahyani, Anton Muhibuddin, 2014. Eksplorasi mikoriza vesikular arbuskular (mva) indigenous pada Tanah Aluvial di Kab. Pamekasan Madura. Jurnal Sains dan Seni Pomits. Vol 3(1): 22-25.

Nusantara, A. D., Y. H. Bertham dan I. Mansur. 2012. Bekerja Dengan Fungi Mikoriza Arbuskula. Seameo Biotrop (Southeast Asean Regimal Centre for Tropical Biology).
Rumambi, A. 2012. Penyediaan Pakan Berkelanjutan Melalui Inokulasi Fungi Mikoriza Arbuskula dan Aplikasi Fosfat Alam Pada Arachis pintoi cv. Amarillo dalam tumpang sari dengan jagung (Zea mays L) atau sorgum (Sorghum bicolar L, Moench). Disertasi Sekolah Pasca Sarjana. Institut Pertanian Bogor.

Setiadi, Y. 1989. Proses Pembentukan VA Mikoriza. Makalah kursus Singkat Tehnologi Mikoriza. Kerjasama PAU Bioteknologi IPB - PAU Bioteknologi UGM. Bogor

Setiadi, Y. 1990. Mengenal Fungi Mikoriza dan Prospek aplikasinya sebagai pupuk biologis untuk meningkatkan pertumbuhan dan kualitas semai tanaman kehutanan. Makalah "Lokakarya system produksi bibit sevara missal", 1819 september 1996. Bogor.

Setiadi. Y. dan A. Setiawan. 2011. Studi status fungi mikoriza arbuskula di areal rehabilitas pasca penambangan nikel (Studi Kasus PT INCO Tbk. Orowako, Sulawesi Selatan). Jurnal Silvikultur Tropika, Vol. 3(01):88-95.

Suamba, I. W., I G. P. Wirawan, Wayan Adiartayasa, 2014. Isolasi dan identifikasi mikroskopis pada Rhizosfer Tanaman Jeruk (Citrus sp) di Desa Kerta, Kecamatan Payangan Kab. Gianyar. Jurnal Agroekoteknologi Tropika Vol. 201(4): 201-207.

Sundari. 2011. Isolasi dan Identifikasi Mikoriza Indegenous dari Perakaran Tembakau Sawah (Nicotiana tabacum L) di area Persawahan Kabupaten Pamekasan Madura. 
Widiastuti, H. dan K. Kramadibrata. 1992. Jamur mikoriza bervesikulaarbuskula di beberapa tanah masam dari Jawa Barat. Menara Perkebunan, Vol. 60(1):9-19.

Wulandari, G. Suwirmen dan Z. A. Noli. 2014. Kompatibilitas spora glomus hasil isolasi dan Rizosfer Macaranga triloba dengan tiga jenis tanaman pakan. Jurnal biologi Universitas Andalas Vol.3(2): 116122. 